\title{
Image-guided interstitial high-dose-rate brachytherapy in the treatment of metastatic esophageal squamous cell carcinoma
}

\author{
Jazan Omari, MD', Constanze Heinze, MD!, Antje Wilck', Peter Hass, MD², Max Seidensticker, MD³, Robert Damm, MD!, \\ Katharina Fischbach, MD!, Jens Ricke, MD³, Maciej Pech, MD',4, Maciej Powerski, MDl \\ 'Department of Radiology and Nuclear Medicine, Otto-von-Guericke University, Magdeburg, Germany, ${ }^{2}$ Department of Radiation Oncology, \\ Otto-von-Guericke University, Magdeburg, Germany, ${ }^{3}$ Department of Radiology, University Hospital Munich, Munich, Germany. \\ ${ }^{4} 2^{\text {nd }}$ Department of Radiology. Medical University of Gdansk, Gdansk, Poland
}

\begin{abstract}
Purpose: To evaluate the efficacy of computed tomography (CT)- and magnetic resonance imaging (MRI)-guided interstitial high-dose-rate brachytherapy $(\mathrm{HDR}$ IBT $=$ IBT) in patients with metastatic esophageal squamous cell carcinoma.

Material and methods: Eleven patients with 21 unresectable metastases of histologically proven esophageal squamous cell carcinoma were included in this retrospective study. Fourteen visceral and 7 lung metastases were treated with image-guided (CT or open MRI guidance) IBT using a ${ }^{192}$ Iridium source (single fraction irradiation). Clinical and imaging follow-up were performed every 3 months after treatment. Primary endpoint was local tumor control (LTC) and safety. Furthermore, we analyzed safety, progression-free survival (PFS), and overall survival (OS).

Results: The median diameter of the target lesions was $2.2 \mathrm{~cm}$ (range: $0.7-6.8 \mathrm{~cm}$ ), treated with a median $\mathrm{D}_{100}$ of 20.1 Gy (range: 10-25 Gy). During a median follow-up of 6.3 months (range: 3-21.8 months), three patients displayed local recurrences, resulting in LTC of $85.7 \%$. Median PFS was 3.4 months and median OS after IBT was 13.7 months. No severe adverse events (grade $3+$ ) requiring hospitalization or invasive intervention were recorded.

Conclusions: Image-guided IBT is a safe and effective treatment in patients with metastasized esophageal squamous cell carcinoma.

J Contemp Brachytherapy 2018; 10, 5: 439-445 DOI: https://doi.org/10.5114/jcb.2018.79230
\end{abstract}

Key words: esophageal cancer, image-guided intervention, interventional oncology, interstitial brachytherapy, metastases.

\section{Purpose}

Esophageal cancer (EC) is the eighth most common cancer worldwide. With an overall 5-year survival rate of $15-25 \%$, it is the sixth leading cause of cancer-associated mortality [1]. These epidemiological data include both histological subtypes: adenocarcinoma (AC) and squamous cell carcinoma (SCC), which is the predominant type [2]. Multimodal therapy combining (neoadjuvant) chemo-/radiotherapy and resection improves the outcome in non-metastatic patients [3]. However, up to $88.9 \%$ of the patients develop metastases within 3 years after curative surgery, with a median disease-free interval after surgery of 1 year $[4,5,6,7]$. Due to limited therapy options, the prognosis after recurrence is extremely poor, with a median survival of 3-7 months $[8,9,10]$. Moreover, guidelines from the European Soci- ety for Medical Oncology (ESMO) report that palliative chemotherapy for stage IV patients is less effective for SCC than for AC. Cisplatin-based combinations tend to show an increased response rate but no benefit regarding survival; therefore, either best supportive care or monotherapy should be considered in ESCC [11]. In contrast, in various tumor entities metastases limited in number and extent (i.e. oligometastases) are increasingly considered suitable for localized therapy with possible curative intent or at least systemic control, e.g. colorectal cancer $[12,13]$. Such localized therapy might include surgery but also image-guided local ablation techniques like radiofrequency ablation or high-dose-rate brachytherapy (IBT). However, resection is not possible in majority of patients due to distribution of metastases, contraindications for surgery, or general anesthesia, apart from surgery-associated morbidity and mortality. IBT of parenchymal or-

Address for correspondence: Constanze Heinze, MD, Department of Radiology and Nuclear Medicine, Received: 06.07.2018 Otto-von-Guericke University, Leipziger Strasse 44, 39120 Magdeburg, Germany, phone: +49 391 6713030, Accepted: 22.09 .2018 fax: +49391 6713029, e-mail: constanze.heinze@med.ovgu.de 
gans is a relatively new technique, where an ${ }^{192}$ Iridium source is inserted directly in metastatic lesion through percutaneously implanted applicators, placed in an image-guided minimal invasive intervention, and allowing a well-defined single fraction irradiation of the target volume. IBT has already been shown to be an efficient, yet gentle treatment with a minimum of complications in ablation of metastases of various tumors, e.g. colorectal cancer or malignant melanoma, or even gastroesophageal adenocarcinoma $[14,15,16]$. To our knowledge, no data has been published so far evaluating the efficacy of IBT in the treatment of visceral and lung metastases of SCC. In this study, we analyzed safety and efficacy in a cohort of 11 patients with 21 unresectable SCC metastases, who underwent image-guided IBT.

\section{Material and methods}

\section{Eligibility criteria and patients}

Inclusion criteria were: 1 . Technically unrespectable metastases; 2 . Surgery refusal or medical contraindication for resection or comorbidities; 3 . The Eastern Cooperative Oncology Group (ECOG) performance status below 2;
4. Appropriate coagulation parameters (i.e. platelet count above $50000 / \mathrm{nl}$, Quick > 50\%, partial thromboplastin time $>5$ seconds) and liver parameters (bilirubin $<30 \mu \mathrm{mol} / \mathrm{l}) ; 5$. Sufficient lung capacity in case of ablation of pulmonary metastases $\left(\mathrm{FEV}_{1}>1.5 \mathrm{l}\right)$. There were no limitations placed upon size or location of the lesions. Contraindications were as follows: 1. Peritoneal carcinomatosis; 2. Extensive uncontrollable systemic disease; 3. Lack of consent. With respect to these criteria, we included 11 patients in this retrospective study (all male; mean age: 64.7 years; range: $52-77$ ) with 21 unresectable metastases, treated with computed tomography (CT)and magnetic resonance imaging (MRI)-guided IBT between April 2009 and June 2017. We treated a total of 14 visceral metastases (including 9 liver lesions, 4 lymph node metastases, and one lesion located in the adrenal gland) and 7 lung metastases. A positive opinion from the ethics committee for the analysis of the patients' data was obtained. All patients were discussed in an interdisciplinary tumor conference, where the indication for IBT was determined. All patients were presented with histologically proven SCC and displayed tumor progression at the time of referral to our institution.

Table 1. Patients characteristics

\begin{tabular}{|c|c|c|c|c|c|c|c|c|c|c|}
\hline Patient & Sex & $\begin{array}{c}\text { Age } \\
\text { (years) }\end{array}$ & M1 & $\begin{array}{c}\text { Chemotherapy } \\
\text { before IBT }\end{array}$ & $\begin{array}{c}\text { Localization } \\
\text { of target } \\
\text { lesion }\end{array}$ & $\begin{array}{l}\text { Num- } \\
\text { ber of } \\
\text { lesions }\end{array}$ & $\begin{array}{c}\text { Max } \\
\text { diameter } \\
\text { (cm) }\end{array}$ & $\begin{array}{c}\text { Number of } \\
\text { caterers } \\
\text { used } \\
\text { per lesion }\end{array}$ & $\begin{array}{l}\text { Dose appl. } \\
\text { (Gy) }\end{array}$ & $\begin{array}{l}\text { Median } \\
\text { follow-up } \\
\text { (months) }\end{array}$ \\
\hline 1 & $M$ & 59 & synchron & $\begin{array}{c}\text { carboplatin, } \\
\text { paclitaxel }\end{array}$ & liver & 1 & 4.1 & 3 & 20.5 & 3.1 \\
\hline 2 & $M$ & 52 & metachron & $\begin{array}{l}\text { cisplatin, } \\
\text { fluorouracil }\end{array}$ & $\begin{array}{l}\text { lung, lymph } \\
\text { node }\end{array}$ & 2 & $5.8 / 2.6$ & $3 / 2$ & $11.3 / 10$ & 3.2 \\
\hline 3 & $M$ & 77 & metachron & $\begin{array}{l}\text { carboplatin, } \\
\text { paclitaxel, } \\
\text { cisplatin, } \\
\text { fluorouracil }\end{array}$ & liver & 1 & 6.3 & 5 & 22.5 & 5.6 \\
\hline 4 & $M$ & 72 & metachron & $\begin{array}{l}\text { carboplatin, } \\
\text { paclitaxel, } \\
\text { cisplatin, } \\
\text { fluorouracil }\end{array}$ & $\begin{array}{l}\text { adrenal } \\
\text { gland }\end{array}$ & 1 & 3.4 & 3 & 20.1 & $\begin{array}{c}6.9 \\
\text { (ongoing) }\end{array}$ \\
\hline 5 & $M$ & 67 & metachron & $\begin{array}{l}\text { cisplatin, } \\
\text { fluorouracil }\end{array}$ & lung, liver & 4 & $\begin{array}{l}1.8 / 0.7 / \\
0.7 / 5.8\end{array}$ & $1 / 1 / 1 / 5$ & $\begin{array}{l}21.9 / 22.8 / \\
25.3 / 14.3\end{array}$ & 7.3 \\
\hline 6 & M & 52 & synchron & $\begin{array}{l}\text { cisplatin, } \\
\text { fluorouracil }\end{array}$ & lung & 1 & 2.7 & 2 & 20.9 & 6.3 \\
\hline 7 & M & 71 & metachron & NOS & lymph node & 1 & 1.4 & 5 & 15.4 & 14.7 \\
\hline 8 & $M$ & 63 & metachron & $\begin{array}{l}\text { cisplatin, } \\
\text { fluorouracil }\end{array}$ & liver & 1 & 6.8 & 7 & 20.0 & 3.3 \\
\hline 9 & M & 77 & metachron & $\begin{array}{l}\text { cisplatin, } \\
\text { fluorouracil }\end{array}$ & lymph node & 2 & $2.2 / 2.0$ & $1 / 1$ & 20.1/19.3 & 10.1 \\
\hline 10 & $M$ & 63 & metachron & $\begin{array}{l}\text { etoposid, } \\
\text { cisplatin, } \\
\text { fluorouracil }\end{array}$ & liver & 5 & $\begin{array}{c}3.4 / 2.7 / \\
1.2 / 0.9 / 1.9\end{array}$ & $2 / 1 / 1 / 1 / 2$ & $\begin{array}{c}21.2 / 17.1 / \\
22.5 / 22.7 / \\
17.8\end{array}$ & 4.7 \\
\hline 11 & $M$ & 59 & synchron & NOS & lung & 2 & $1.1 / 0.9$ & $1 / 1$ & $22.2 / 15.7$ & 21.7 \\
\hline
\end{tabular}

All patients underwent either surgery or irradiation of the primary tumor prior to local ablation.

Patient No 1 and No 9 received palliative chemotherapy in the time between interstitial high-dose-rate brachytherapy (HDR IBT =IBT) and progression. Furthermore, patient No 9 was treated with RFA of the lung 3 months after IBT

IBT - interstitial brachytherapy; NOS - not otherwise specified 
Prior to local ablation, ten patients received radiation of the primary tumor and 4 patients underwent surgical resection of the primary tumor. Furthermore, all patients had undergone palliative or adjuvant chemotherapy before IBT (detailed patient characteristics are presented in Table 1). Due to the size and location, two liver lesions were treated with MRI-guided IBT (maximum diameter $1.2 \mathrm{~cm}$ and $1 \mathrm{~cm}$, respectively) and other lesions were visualized with CT. Prior to local ablation, all patients received a full clinical status evaluation with a physical examination, laboratory assessment, whole body contrast enhanced CT, and a Gb-EOB-DTPA enhanced MRI of the liver (Primovist ${ }^{\circledR}$, Bayer, Pharma, Leverkusen, Germany). All patients undergoing IBT of lung lesions had a clinically full-compensated lung function.

\section{Study design and statistical analysis}

Primary endpoint was local tumor control; secondary endpoints were safety, overall survival, and progression-free survival. The results were analyzed in a nonrandomized and retrospective approach. Local tumor control (LTC), overall survival (OS), and progression-free survival (PFS) were evaluated using the Kaplan-Meier method with SPSS (IBM Corp. released 2013; IBM SPSS Statistics for Windows, version 22.0. Armonk, NY, IBM Corp). Safety was evaluated descriptively.

\section{Interventional technique and irradiation}

The applied methodology has been described in detail elsewhere $[17,18]$. In short, under guidance of a fluoroscopy-CT (Toshiba, Aquilion, Japan) or real-time MRI at 1.0 T (Panorama 1.0 T, open MR system, Philips Healthcare), 18-gauge needle were placed into target lesions. Subsequently, a flexible 6F catheter sheath (Radifocus, Terumo $^{\mathrm{TM}}$, Tokyo, Japan) was inserted over a stiff angiography guide wire (Amplatz, Boston Scientific, Marl- borough, USA) using Seldinger's-technique, followed by the placement of a $6 \mathrm{~F}$ afterloading catheter (Afterloadingkatheter, Primed ${ }^{\circledR}$ Medizintechnik $\mathrm{GmbH}$, Halberstadt, Germany), which ends were secured to the skin with a suture and covered with sterile bandages. The described procedure was performed under a local anesthesia (lidocaine), sedation (midazolam), and analgesia (fentanyl). After catheter positioning, a contrast-enhanced CT in breath-holding technique or a gadolinium-based MRI scan were obtained to confirm correct catheter positioning and for the purpose of treatment planning. On the acquired images, the target volume was outlined precisely as gross tumor volume (GTV), the clinical target volume (CTV), and adjacent organs at risk (OAR) were marked by the interventional radiologist and the radiooncologist. Treatment planning was performed using Oncentra (Oncentra ${ }^{\circledR}$ Brachy treatment planning system, Elekta $A B$, Stockholm, Sweden). Automatically calculated isodose lines - relative to the CTV - were controlled and adapted slice by slice. All irradiations were applied as a single fraction irradiation using an iridium-192 source, with a nominal activity of $10 \mathrm{Ci}$. A reference dose of 15-20 Gy was intended in our patients, which was defined as the minimum dose enclosing the CTV completely $\left(D_{100}\right)$. Higher doses inside the tumor volume were permitted and not limited. Dose limitations were taken into account independent of adjacent organs at risk, for example gastric or duodenal wall $(<15 \mathrm{~Gy} / \mathrm{ml})$. After irradiation, the catheters were removed, and the puncture tracts were sealed using gelfoam or fibrin tissue glue. Figure 1 illustrates the interventional technique and irradiation planning.

\section{Follow-up}

Clinical, laboratory, and imaging follow-up (contrast enhanced whole body CT and Gb-EOB-DTPA enhanced MRI of the liver - in case of treated hepatic metastases) was performed every three months after treatment. Lo-
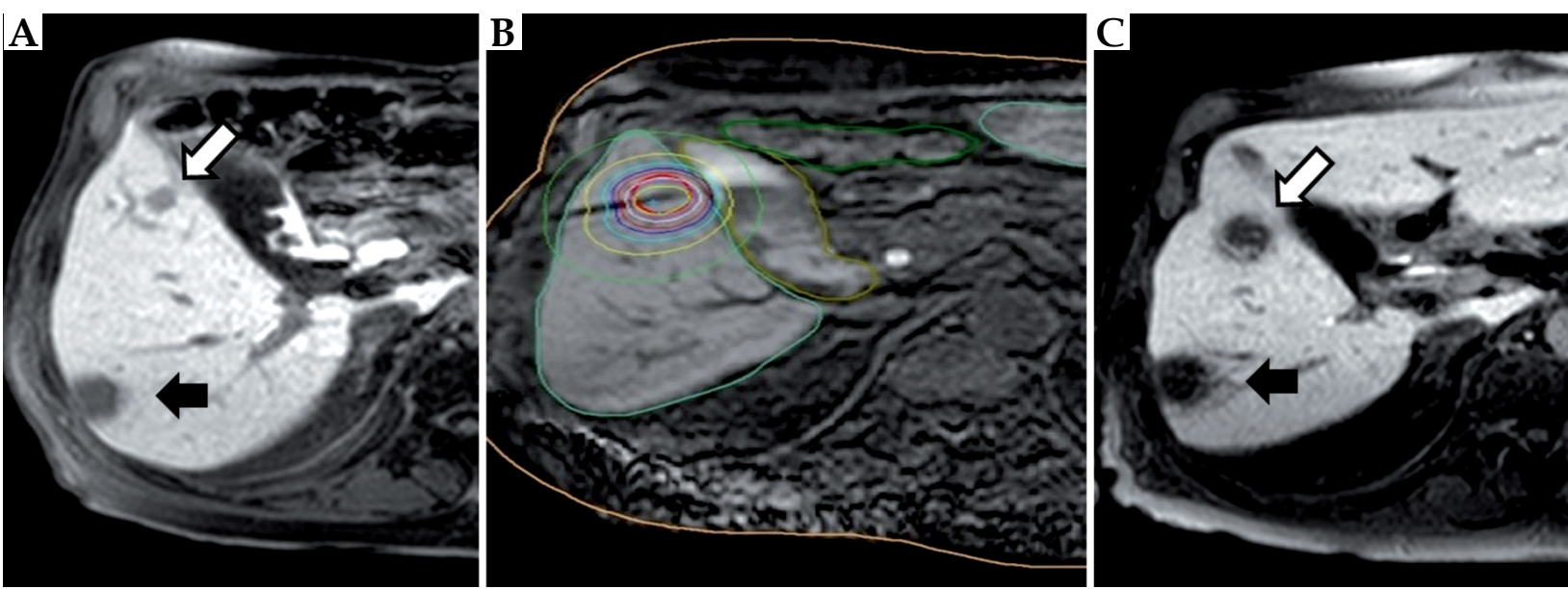

Fig. 1. A) Gd-EOB-DTPA enhanced T1w MRI of a patient with liver metastasis from esophageal squamous cell carcinoma and sequential treatment with interstitial high-dose-rate brachytherapy $($ HDR IBT $=$ IBT). White arrow indicates lesion planned for IBT and black arrow shows characteristic Gd-EOB-DTPA enhancement defect after irradiation of a metastases 2 weeks before; B) Planning MRI with marked target lesion (red line), isodose lines, and catheters; C) 3 months follow-up: white arrow indicate lesion treated with Gd-EOB-DTPA enhancement defect and black arrow indicate first treated lesion with constant Gd-EOBDTPA enhancement defect after IBT 
cal tumor control and PFS were assessed by employing RECIST criteria (RECIST version 1.1). Overall survival was calculated from the day of ablation to death. Adverse events were defined according to the Common Terminology Criteria for Adverse Events (CTCAE) version 4.03.

\section{Results}

The median diameter of 21 metastases was $2.2 \mathrm{~cm}$ (range: $0.7-6.8 \mathrm{~cm}$ ). A mean of 2.3 catheters per lesion (range: 1-7) was employed to achieve full coverage of the target lesion. Ten patients were treated in one session. One patient received 2 sessions: patient No 5 developed a solitary liver metastasis 4 months after first IBT of pulmonary and nodal lesions, and thereupon received a local treatment of the liver. The intended minimum tumor dose $\left(D_{100}\right)$ was 15-20 Gy, depending on localization: retroperitoneal lymph node and adrenal gland were intended to treat with $15 \mathrm{~Gy}$, whereas $20 \mathrm{~Gy}$ was prescribed for liver and lung malignancies. The median $\mathrm{D}_{100}$ administered was 20.1 Gy (range: $10-25 \mathrm{~Gy}$ ). In some cases, the $\mathrm{D}_{100}$ had to be lowered to protect adjacent risk structures. Full dose coverage of the GTV was achieved in 5 lung lesions and 6 liver lesions (20 Gy, respectively), and a minimum of $15 \mathrm{~Gy}$ was reached in 4 lymph node metastases (including retroperitoneal space) as well as in the lesion of the adrenal gland. During the treatment, no adjacent OAR were irradiated in excess of critical value. The mean irradiation time was $28 \mathrm{~min}$ (range: 11-68 $\mathrm{min}$ ). The mean hospital stay of the patients was 4.4 days (range: $2-7$ days). None of the patients experienced grade III+ adverse events requiring interventions, surgery, or hospitalization. However, 4 patients received peri-interventional intravenous antibiosis (ciproflaxacin and metronidazole) to reduce the risk of a possible infection, e.g. due to treatment of a central liver lesion. The median follow-up time was 6.3 months (range: 3-21.8 months). Three patients displayed local recurrence of the target lesion in the timespan of 3-7 months after IBT, resulting in a local tumor control of $85.7 \%$ in the Kaplan-Meier analysis (Figure 2A). The recurrent lesions were 2 lung lesions and 1 liver metastasis; these lesions were covered with a minimum tumor dose of $\geq 20$ Gy at time of treatment. The progression-free interval for all patients ranged from 1.3 to 13 months, with a median of 3.4 months (Figure 2B). During the follow-up period, all patients displayed a progressive systemic disease: 3 patients showed intrahepatic progression $(27.3 \%)$, 3 patients presented pulmonary progression $(27.3 \%)$, and 5 patients demonstrated progression in various locations ( $45.4 \%$; i.e. lymph node, retroperitoneal space, bone). At the date of censoring, one patient of the analyzed population was still alive (Patient No. 4 received treatment in June 2017). The median OS of the 10 remaining patients after IBT was 13.7 months (range: 5.6-25.7 months, Figure 2C). Median survival after recurrence was 6 months (range: 1-22 months, Figure 2D).

\section{Discussion}

Within 3 years after curative surgery, up to $88.9 \%$ of patients with EC develop metastases, with a median dis- ease-free interval of 1 year after resection $[4,5,6,7]$. The post-recurrence survival is extremely poor, with a reported median survival of approximately 3-7 months $[8,19,20]$. Therapy options are limited and according to the ESMO guidelines, a recommendation can be neither made for a first- nor for a second-line palliative chemotherapy in stage IV patients with SCC [11]. More recently, a phase-3, double-blind, placebo-controlled randomized trial with 450 patients failed to show a benefit of gefitinib on overall survival [20].

Whereas surgical resection is the method of choice in oligometastatic colorectal liver metastases, evidence for surgical resection of EC metastases is scarce [21,22]. Nevertheless, in metastatic EC, long-term survivors have been reported after resection of liver metastases in a curative intent [23]. Moreover, in 2017, van Daele et al. retrospectively analyzed the outcome of 12 stage IV patients with EC, after a multimodal and aggressive treatment including surgery [24]. Furthermore, after a median follow-up of 22 months (range: 8-50), 50\% of the surgical patients were still alive. These findings suggest that highly selected candidates benefit from an aggressive curative approach, even in stage IV patients.

However, surgical resection is available in a limited number of cases (for instance in colorectal cancer), a curative resection of liver metastases is not possible in approximately $80 \%$ of the cases [21] but if possible, it is also linked to surgery-associated morbidity and mortality, regarding the extent of resection and the remaining functioning liver tissue. It results in prolonged stay in the hospital, for instance in the study mentioned above, the median post-operative hospital stay was 15 days (range: 11-52 days).

In contrast, image-guided IBT provides a safe and minimal invasive approach. In the literature for patients undergoing local ablation of liver lesions or metastases of the retroperitoneal space, grade III-IV adverse events (i.e. bleeding, requiring angiographic embolization) occurred in up to $3 \%$, grade I and II toxicities (e.g. nausea, emesis, unspecified abdominal pain) were reported in up to $29 \%[18,25]$. In the study herein, we did not report any severe adverse event (grade III+) requiring invasive intervention. The mean hospital stay was 4.4 days. In general, patients tolerated the treatment well and could be discharged earlier, but due to the risk of occult bleeding, an observation of at least 48 hours after ablation was considered necessary.

To our knowledge, there is a limited number of studies investigating the efficacy and outcome of patients with metastatic EC treated with local ablation. Matsui et al. retrospectively evaluated LTC of 21 patients, with a total of 31 pulmonary metastases (mean size, $1.7 \mathrm{~cm}$ ) treated with percutaneous radiofrequency ablation (RFA) [26]. The authors reported LTC rate of $74.2 \%$ after a median interval of 4.8 months post-RFA. Baba et al. showed a better LTC of $83 \%$ at 12 months after RFA of pulmonary SCC metastases [27].

In contrast, IBT has primarily been evaluated in metastatic colorectal cancer and in hepatocellular carcinoma (HCC), demonstrating LTC rates of $88.3 \%$ after 12 months 
A

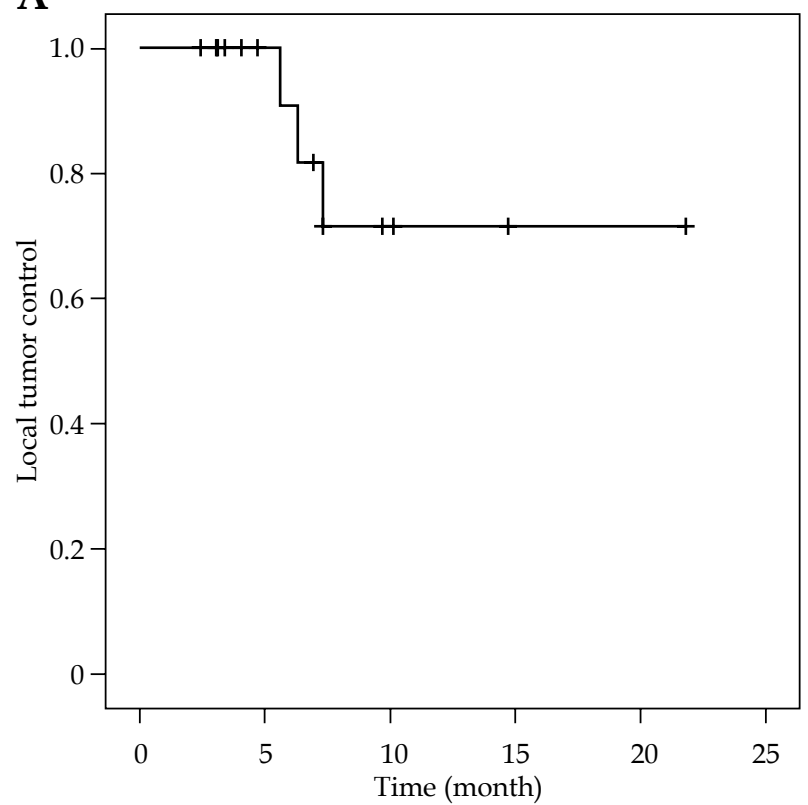

C

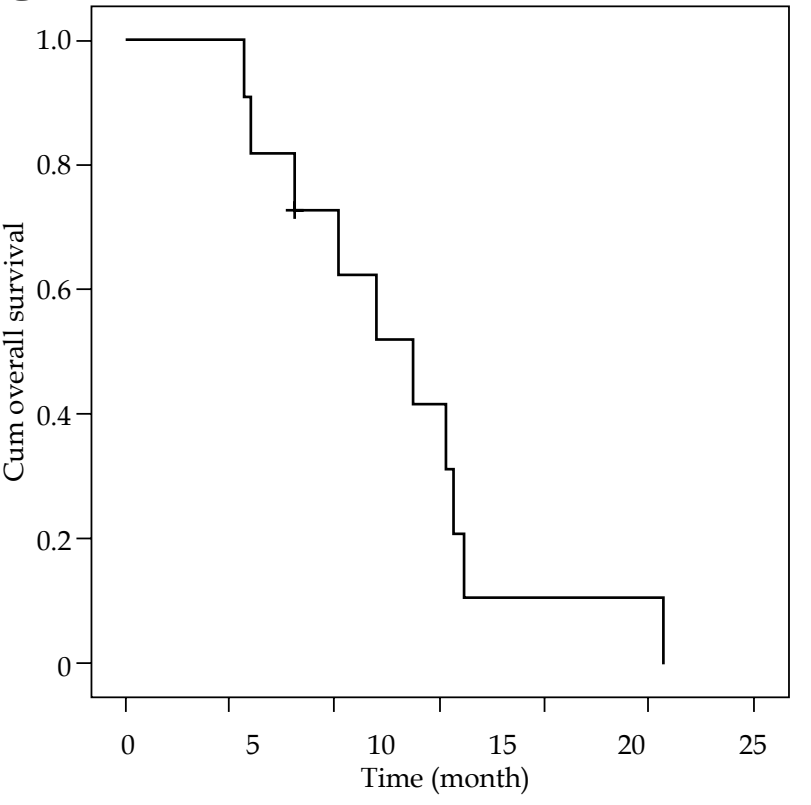

B

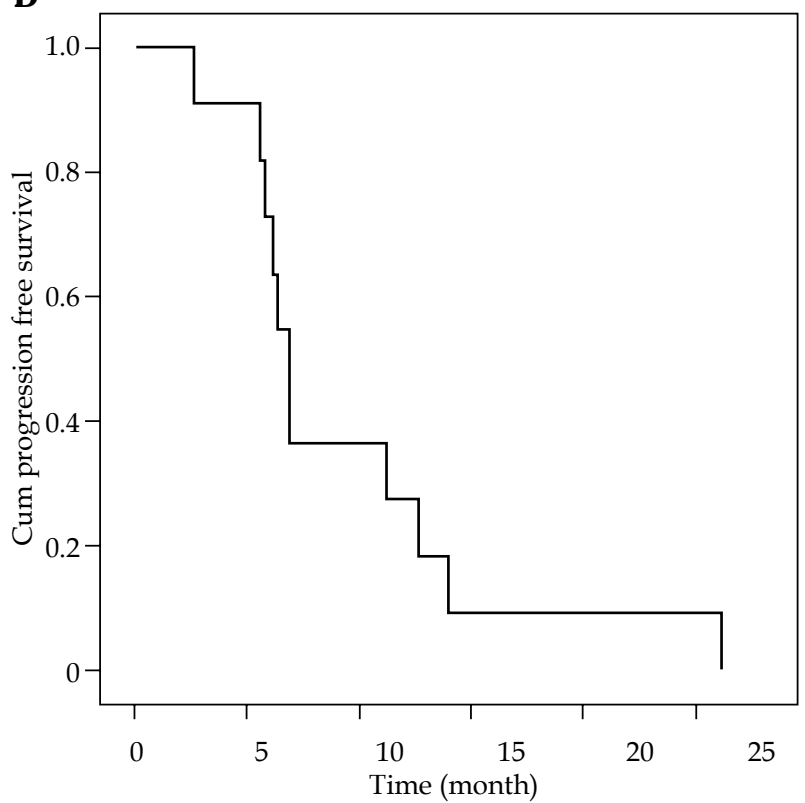

D

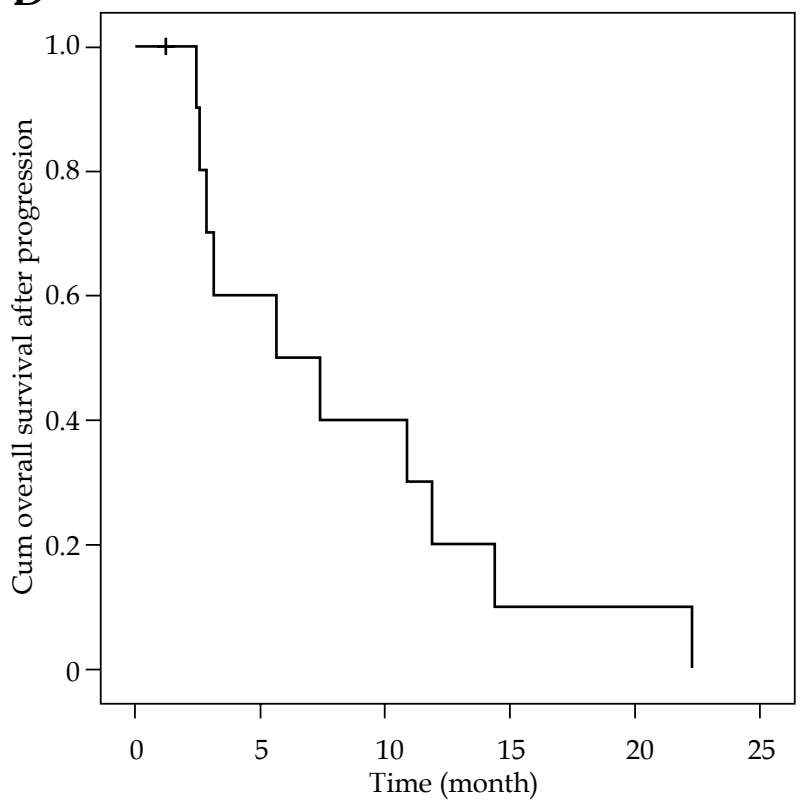

Fig. 2. Kaplan-Meier curves show A) local tumor control and B) progression-free survival of patients with squamous cell carcinoma metastases ablated with interstitial high-dose-rate brachytherapy. Overall survival and overall survival after tumor progression of the same patients is depicted in C), and D) Censoring is indicated by crosses

for colorectal lesions and up to $95 \%$ for $\operatorname{HCC}[15,17,28]$. Moreover, in metastatic malignant melanoma, the LTC rate was reported to be $90 \%$ after a median follow-up period of 5 months [14]. Furthermore, for metastases of gastric or esophageal adenocarcinoma, Geisel et al. showed LTC rate of $100 \%$ over a median follow-up of 6.1 months post IBT [16]. In our study, we report a local tumor control of $85.7 \%$ after a median follow-up of 6.3 months. The reported difference might be due to very small patients' population and relatively short follow-up period. Therefore, it can be assumed that our findings go in line with the existing literature. Moreover, our findings correspond to the results of RFA studies mentioned above, even providing a better LTC compared to the investigation of Matsui et al. However, RFA has well known technical limitations leading to a possible incomplete ablation, including a large tumor mass (maximal tumor diameter of $5 \mathrm{~cm}$ ) and major vessels close to the target volume inducing a potential cooling effect. Additionally, adverse events can occur due to the vicinity to critical heat sensitive organs (e.g. bile duct, ureter, liver hilum). IBT in contrast is independent of these restrictions. 
To our knowledge, there are only a few studies investigating the use of stereotactic body radiation therapy (SBRT) in the treatment of visceral or pulmonary metastases of EC: two case reports combining SBRT and palliative chemotherapy $[29,30]$, and two studies investigating the effect of SBRT in oligometastatic disease and in solitary/limited number of nodal metastases, both studies including lesions of any primary site, i.e. 2 and 1 patients with EC, respectively [31,32].

A widespread systemic progression is known to be the major limiting factor for survival, concluding that our finding of a median PFS of 3.4 months emphasizes the poor overall survival of patients with metastasized EC. Consistently, Geisel et al. reported a median PFS of 3.5 months in patients with metastatic esophageal adenocarcinoma after IBT [16].

In our study, we report a median overall survival of 13.7 months after IBT, with a range of 5.6-25.7 months. These findings underline that the impact of local ablation on overall survival is not yet clarified, especially considering the fact that in metastasized SCC, chemotherapeutic options are missing. After recurrence, the survival was poor with a median of 6 months corresponding to the findings in the literature [8]. Nevertheless, we also report one long-term survivor with 25 months. After an aggressive multimodal approach including surgery, van Daele et al. reported a median OS of 22 months indicating possible long-term survival of selected stage IV patients [24]. To identify appropriate candidates that might benefit from local ablation with the intent to extend survival, a prospective trial is needed.

Therefore, the limitations of the study include its retrospective nature and the low number of patients as well as relatively short follow-up. However, to our knowledge, there is little data regarding local ablation of metastatic EC and despite its limitations, the results of this study demonstrate that IBT can be safely and effectively used in the local control of metastasized SCC. Moreover, together with the findings of van Daele et al., this investigation provides an indication that a more aggressive approach could improve the overall survival of highly selected stage IV patients, with an emphasis on the advantage that IBT is a well-tolerated procedure with few side effects.

\section{Conclusions}

We conclude that high-dose-rate brachytherapy is a safe and well-tolerated treatment in the local tumor control of patients with metastasized squamous cell carcinoma.

\section{Disclosure}

Authors report no conflict of interest.

\section{References}

1. Ferlay J, Soerjomataram I, Dikshit R et al. Cancer incidence and mortality worldwide: sources, methods and major patterns in GLOBOCAN 2012. Int J Cancer 2015; 136: 359-386.

2. Jain S, Dhingra S. Pathology of esophageal cancer and Barrett's esophagus. Ann Cardiothorac Surg 2017; 6: 99-109.
3. Van Rossum PSN, Mohammad NH, Vleggaar FP et al. Treatment for unresectable or metastatic oesophageal cancer: current evidence and trends. Nat Rev Gastroenterol Hepatol 2018; 15: 235-249.

4. Nakagawa S, Kanda T, Kosugi $S$ et al. Recurrence pattern of squamous cell carcinoma of the thoracic esophagus after extended radical esophagectomy with three-field lymphadenectomy. J Am Coll Surg 2004; 198: 205-211.

5. Mariette C, Balon JM, Piessen G et al. Pattern of recurrence following complete resection of esophageal carcinoma and factors predictive of recurrent disease. Cancer 2003; 97: 16161623.

6. Hulscher JB, van Sandick JW, Tijssen JG et al. The recurrence pattern of esophageal carcinoma after transhiatal resection. J Am Coll Surg 2000; 191: 143-148.

7. Kunisaki C, Makino H, Takagawa R et al. Surgical outcomes in esophageal cancer patients with tumor recurrence after curative esophagectomy. J Gastrointest Surg 2008; 12: 802-810.

8. Abate E, DeMeester SR, Zehetner J et al. Recurrence after esophagectomy for adenocarcinoma: defining optimal follow-up intervals and testing. J Am Coll Surg 2010; 210: 428-435.

9. Dresner SM, Griffin SM. Pattern of recurrence following radical oesophagectomy with two-field lymphadenectomy. $\mathrm{Br}$ J Surg 2000; 87: 1426-1433.

10. Blom RL, Lagarde SM, van Oudenaarde K et al. Survival after recurrent esophageal carcinoma has not improved over the past 18 years. Ann Surg Oncol 2013; 20: 2693-2698.

11. Lordick F, Mariette C, Haustermans K et al. Oesophageal cancer: ESMO Clinical Practice Guidelines for diagnosis, treatment and follow-up. Ann Oncol 2016; 27: v50-v57.

12. Weichselbaum RR, Hellman S. Oligometastases revisited. Nat Rev Clin Oncol 2011; 8: 378-382.

13. Aigner F, Pratschke J, Schmelzle M. Oligometastatic disease in colorectal cancer - how to proceed. Visc Med 2017; 33: 2328.

14. Bretschneider T, Mohnike K, Hass P et al. Efficacy and safety of image-guided interstitial single fraction high-dose-rate brachytherapy in the management of metastatic malignant melanoma. J Contemp Brachytherapy 2015; 7: 154-160.

15. Collettini F, Lutter A, Schnapauff D et al. Unresectable colorectal liver metastases: percutaneous ablation using CT-guided high-dose-rate brachytherapy (CT-HDBRT). Rofo 2014; 186: 606-612.

16. Geisel D, Denecke T, Collettini F et al. Treatment of hepatic metastases from gastric or gastroesophageal adenocarcinoma with computed tomography-guided high-dose-rate brachytherapy (CT-HDRBT). Anticancer Res 2012; 32: 5453-5458.

17. Ricke J, Wust P, Stohlmann A et al. CT-guided interstitial brachytherapy of liver malignancies alone or in combination with thermal ablation: phase I-II results of a novel technique. Int J Radiat Oncol Biol Phys 2004; 58: 1496-1505.

18. Bretschneider T, Ricke J, Gebauer B, Streitparth F. Image-guided high-dose-rate brachytherapy of malignancies in various inner organs - technique, indications, and perspectives. J Contemp Brachytherapy 2016; 8: 251-261.

19. Parry K, Visser E, van Rossum PS et al. Prognosis and treatment after diagnosis of recurrent esophageal carcinoma following esophagectomy with curative intent. Ann Surg Oncol 2015; 22 (Suppl 3): S1292-1300.

20. Dutton SJ, Ferry DR, Blazeby JM et al. Gefitinib for oesophageal cancer progressing after chemotherapy (COG): a phase 3, multicentre, double-blind, placebo-controlled randomised trial. Lancet Oncol 2014; 15: 894-904.

21. Garden OJ, Rees M, Poston GJ et al. Guidelines for resection of colorectal cancer liver metastases. Gut 2006; 55: iii1-iii8.

22. Nguyen KT, Laurent A, Dagher I et al. Minimally invasive liver resection for metastatic colorectal cancer: a multi-insti- 
tutional, international report of safety, feasibility, and early outcomes. Ann Surg 2009; 250: 842-848.

23. Huddy JR, Thomas RL, Worthington TR, Karanjia ND. Liver metastases from esophageal carcinoma: is there a role for surgical resection? Dis Esophagus 2015; 28: 483-487.

24. Van Daele E, Scuderi V, Pape E et al. Long-term survival after multimodality therapy including surgery for metastatic esophageal cancer. Acta Chir Belg 2018; 118: 227-232.

25. Mohnike K, Neumann K, Hass P et al. Radioablation of adrenal gland malignomas with interstitial high-dose-rate brachytherapy: Efficacy and outcome. Strahlenther Onkol 2017; 193: 612-619.

26. Matsui Y, Hiraki T, Gobara H et al. Percutaneous radiofrequency ablation for pulmonary metastases from esophageal cancer: retrospective evaluation of 21 patients. J Vasc Intero Radiol 2014; 25: 1566-1572.

27. Baba Y, Watanabe M, Kawanaka K et al. Radiofrequency ablation for pulmonary metastases from esophageal squamous cell carcinoma. Dis Esophagus 2014; 27: 36-41.

28. Mohnike K, Wieners G, Schwartz F et al. Computed tomography-guided high-dose-rate brachytherapy in hepatocellular carcinoma: safety, efficacy, and effect on survival. Int J Radiat Oncol Biol Phys 2010; 78: 172-179.

29. Katano A, Yamashita H, Nakagawa K. Stereotactic body radiotherapy for oligo-recurrence in the liver in a patient with esophageal carcinoma: A case report. Mol Clin Oncol 2017; 7: 1061-1063.

30. Egawa T, Okubo Y, Kemmochi T et al. A case of liver metastasis from esophageal cancer treated with stereotactic body radiation therapy. Gan To Kagaku Ryoho 2013; 40: 1850-1852.

31. Milano MT, Katz AW, Zhang H et al. Oligometastases treated with stereotactic body radiotherapy: long-term follow-up of prospective study. Int J Radiat Oncol Biol Phys 2012; 83: 878-886.

32. Yeung R, Hamm J, Liu M, Schellenberg D. Institutional analysis of stereotactic body radiotherapy (SBRT) for oligometastatic lymph node metastases. Radiat Oncol 2017; 12: 105. 